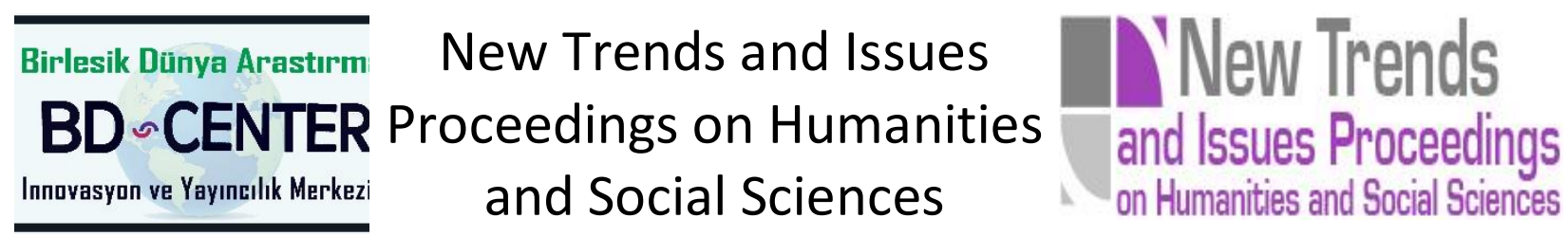

Volume 7, Issue 1, (2020) 210-219

www.prosoc.eu

Selected Paper of 12th World Conference on Educational Sciences (WCES-2020) 06-08 June 2020, Istanbul Ayvansaray

University, Istanbul, Turkey

\title{
Teaching electrical engineering or technology in a fun way
}

\author{
Cestmir Serafin*, Faculty of Education, Palacky University in Olomouc, Olomouc, Czech Republic \\ https://orcid.org/0000-0003-1200-1089
}

\section{Suggested Citation:}

Serafin, C., (2020). Teaching electrical engineering or technology in a fun way. New Trends and Issues Proceedings on Humanities and Social Sciences. 7(1), pp 210-219. DOI: 10.18844/prosoc.v\%vi\%i.4900

Received from October 15, 2019; revised from January 2, 2020; accepted from June 18, 2020.

Selection and peer review under responsibility of Assoc. Prof.Dr. Jesus Garcia Laborda, University of Alcala, Spain. (C)2020 Birlesik Dunya Yenilik Arastirma ve Yayincilik Merkezi. All rights reserved.

\begin{abstract}
Combining physical and mental activities as a prerequisite for a well-rounded personal development is the benefit of technical kits, especially electronic ones. Such a combination also pushes the limits of the students' efficiency. When used correctly, the creativity of both students and teachers is developed on a superior developmental level of knowledge in terms of quality. Electrotechnical kits have many positive effects in school education, suitably supplement as well as support it, and are also one of its subject matters. Considering the fast, global development information technology is experiencing, there is a growing need to combine computer systems and electrotechnical kits in education. The goal of this paper is to provide a comparative and analytical insight into teaching general, primary-level technical subjects in the context of electrical engineering, especially of electrotechnical kits, and to define current trends in or approaches to the implementation of educational activities.
\end{abstract}

Keywords: Technical Education, electrotechnical kits.

* ADDRESS FOR CORRESPONDENCE: Cestmir Serafin, Faculty of Education, Palacky University in Olomouc, Olomouc, Czech Republic. E-mail address: cestmir.serafin@upol.cz / Tel.: +0-000-000-0000 
Serafin, C., (2020). Teaching electrical engineering or technology in a fun way. New Trends and Issues Proceedings on Humanities and Social Sciences. 7(1), pp 210-219. DOI: 10.18844/prosoc.v\%vi\%i.4900

\section{Introduction}

The issue of electrotechnical kits has been debated and published in many professional journals, as well as at international conferences and seminars. A systemic approach to working with electrotechnical kits is examined by a few research studies (Geddes, 2013; Marszalek, 2001). An elementary, general, comprehensive perspective of electrotechnical kits from a terminological and didactic point of view, including their application to teaching, is offered by Dostal (2015). These authors also discuss the above-mentioned issues from the perspective of mutual conversions between function and assembly patterns, as well as by introducing electrotechnical kits into education.

Before we engage in any further analysis, it is only appropriate for us to conduct a conceptual analysis of the electrotechnical kit sphere. This analysis can be carried out from two basic points of view:

1. pedagogical-psychological-defining electrotechnical kits as training aids:

- applying didactic principles (scientificity, combining theory and practice, individual approach, illustrative nature, activities, proportionality and permanency);

- incorporating electrotechnical kits into the system of training aids;

- psychological perception of electrotechnical kits-stage of the students' development, their disability, etc.professional-technical-i.e., the perspective of electrical engineering and

construction (safety, reliability, resistance, easy operation and repairs, etc.) which, however, must

always be linked to a pedagogical perspective in terms of teaching (see below).

What is an electrotechnical kit? Definition of this term must also be approached from two anglespedagogical and technical. The dictionary definition (Knapek \& Titera, 2002) states that construction kits are generally 'unified function parts (blocks) which are mutually physically and logically compatible and facilitate the construction of sets with various uses of an industrial and laboratory nature.' They are 'sets of objects which are supposed to be assembled or connected so that a specific whole can be formed, as well as disassembled.' This is the technical definition of an electrotechnical kit (Feyisayo, Kareem \& Oluwasegun, 2019).).

Vanecek (2016) defined kits as training aids which facilitate the assembly of devices delimited by given parts and their construction, using a presented pattern and/or one's own imagination. According to Novak (1997), when attempting to formulate a more precise definition of electrotechnical kits as training tools-i.e., from the pedagogical (especially didactic) perspective, it is possible to start from the above-mentioned definition, although some of the terms need to be specified or replaced. Therefore, we do not use the term 'set', we rather use 'system', which constitutes a whole, assembled in accordance with certain needs. The term 'object' must also be specified which is why we talk about 'principal elements, functional elements and functional parts' (elaborated below). Finally, it is necessary to specify the part of the original definition which concerns assembly and disassembly, so that it is narrower, but at the same time generally applicable to the area of electrotechnical kits. Novak (1997) defines electrotechnical kits as follows: an electrotechnical kit is a system of support, functional elements and functional parts, intended for a one-time or repeated assembly of various numbers of circuits and defined by its didactic and technical specifications as a whole.

The main goals of using electrotechnical kits in education can be considered to be the introduction of students to the basic knowledge of electrical engineering and electronics, the deepening and expansion of their awareness, as well as the creation and improvement of their work skills and habits. The tasks solved with the use of kits on the basis of acquiring a certain degree of theoretical knowledge help with the development of logical and creative thinking. Furthermore, successful assembly and performance of operations related to correctly closing and operating a circuit, device or apparatus give the students a sense of self-realisation. The use of electrotechnical kits offers a suitable way to develop the technological knowledge of students, to deepen the illustrative nature of teaching and, at the same time, to have students learn simple experimental work. Students find themselves in active contact with 
Serafin, C., (2020). Teaching electrical engineering or technology in a fun way. New Trends and Issues Proceedings on Humanities and Social Sciences. 7(1), pp 210-219. DOI: 10.18844/prosoc.v\%vi\%i.4900

studied phenomena, directly receiving stimuli through their sensory organs and thus specifically learn about the characteristics of the studied phenomena. When engaged in laboratory work, the students cause electrical phenomena and processes to occur, solving tasks and explaining the nature of the studied phenomena which they find hard to explain in terms of theory (this is especially true for electrical engineering). Finally, they arrive at conclusions, natural-scientific and technological theorems, and verify what was deductively communicated to them. This makes classes more interesting to students and the acquired knowledge illustrative (Oyetoro, Grace \& Adesina, 2019).

In this regard, it is appropriate to mention the apparent trend in the approach to the contemporary understanding of education - the constructivist approach. The constructivist theory emphasises the active participation of subjects who do not gain knowledge passively, but rather construct it. The student's knowledge develops as it 'is organised and adapted to the environment in more complex ways' (Hendl, 2005). The constructivist concept of education is based on the activities of students which lead to the development of their cognitive skills, thinking and creativity; the issues of motivation, activity, independence, creativity and humanising education are appreciated and respect is given to the notion that students interpret new facts on the basis of understanding what they learned previously, which is of their existing knowledge and experiences. These mental structures constitute patterns which serve as a foundation for new, constructed knowledge.

When a teacher assumes the constructivist approach to education, they assess and diagnose the students' dispositions and attitudes to the expected content and to the manner of its processing. Subsequently, the teachers adapt their approach to these results (see Hajerova-Mullerova, Doulik \& Skoda (2005) for further details). It is the teacher's responsibility to establish suitable conditions and materials for education to take place, to make it easier for students to construct new knowledge as a part of their education, to respect their individual traits and pace, to ensure that the students are active and to combine their knowledge with activities and skills. All of this can be ideally combined by using electrotechnical kits (Keser \& Semerci, 2019; Yavuz \& Kurt, 2019).

\section{Terms and terminology related to electrotechnical kits}

The sphere of terms and terminology is closely related to terminological issues. In the area of vocational training, such issues are extensively addressed by the works of Stoffa (2000). A narrower terminological analysis of electrotechnical kits is offered by Dostal (2004) who introduces a new term 'elektrostavebnice' or electronic kits which are subsequently divided into four topics by the subject they address, one of the topics being electrotechnical kits. Electrotechnical kits are also present in the system of building sets that share the same foundation, namely electric power (Damy \& Plascencia, 2020).

Here, we focus on electrotechnical kits. Based on the information mentioned earlier, the following terms can be introduced (Novak, 1997):

- an electrotechnical pattern is basically a piece of illustrative material where marks are used to symbolise the device's electrical function parts and the connections between them. The individual marks or parts of the electrotechnical patterns are usually placed on the kits and their components. The design of these marks must naturally conform to relevant standards which define their dimensions. From the perspective of creating technically correct concepts along with didactically functional designs, designing electrotechnical marks can sometimes be an insoluble problem.

- a functional element is a part of the electrical circuit that is capable of performing one of the fundamental functions of electricity (e.g., circuit closer and capacitor). 
Serafin, C., (2020). Teaching electrical engineering or technology in a fun way. New Trends and Issues Proceedings on Humanities and Social Sciences. 7(1), pp 210-219. DOI: 10.18844/prosoc.V\%vi\%i.4900

- a functional unit is a part of the device which has its own mark as well as a practical purpose, but there is no point in dividing it into components with their own independent practical purpose (e.g., engine and integrated circuit).

- a functional whole is the aggregate of functional units which has a function in the device without necessarily constituting a construction whole (e.g., amplifier).

- a functional block is the aggregate of functional units which form a construction whole with a strictly defined practical purpose (e.g., logic circuit).

- a functional part is a functional unit, functional whole or an aggregate of functional units which serves a strictly defined practical purpose within the device without necessarily constituting a construction whole (e.g. rectifier);

- a connection unit can be a functional unit or functional block which constitutes an independent construction whole by means of a support (through the design of the printed circuit, external appearance, dimensions, etc.).

- a support is a part of the kit which is supposed to transmit static power (e.g., printed circuit board).

- a section is any group of elements which includes:

- one or more supports;

- one or more functional parts/one or more functional units;

- one or more functional parts and, at the same time, one or more functional units.

- a common construction foundation defines sections and makes it easier to connect functional elements, units or blocks. It can also constitute a support or connection unit (e.g., modified plastic board and a system of guides). This element does not always have to be present.

It is understandable that every kit comprises sections, contains varying amounts of diverse supports (always), functional elements (always), functional units (always) and connection units (sometimes). In order to better understand the link between electrotechnical kits and the connection pattern (a link which is, among other things, the basis of a student's work with an electronic kit), it is useful to mention basic terms and classifications of electrotechnical patterns from the perspective of school education:

- a general pattern is an electrotechnical pattern which depicts the main parts of the device, their purpose and the connection between them (e.g., general wiring pattern);

- a functional pattern is an electrotechnical pattern which clarifies certain processes within the individual functional parts of the device or within the device as a whole. Its structure must clearly show the sequence of depicted processes (e.g., pattern of a regulation circuit);

- a circuit pattern is an electrotechnical pattern which shows all functional units and their connections and gives one a detailed idea of the device's functions;

- a situation pattern is an electrotechnical pattern which shows the placement of the individual parts of the device.

Electrotechnical patterns play an important role in designing model situations as students simultaneously familiarise themselves with the principles on which a technical device operates, with the construction of this device, its handling and practical use. The most important classification of electrotechnical kits concerns the place of their application (this strategy is followed by manufacturers and reflected in the component foundation and design of the kit, as well as in its price):

- schools-used mainly in the school environment (in different school stages), these kits are very resistant when handled by amateurs, but are rather expensive (manufacturers usually produce them in small batches, using a costly technology) and not necessarily available in the retail network;

- home-hobby articles, used in the interest groups (e.g., children's clubs, children's and youth centres or directly in schools) or at home for work and entertainment. Such kits are produced in large batches, using cheap technology. Manufacturers try to keep the cost as low as possible, 
Serafin, C., (2020). Teaching electrical engineering or technology in a fun way. New Trends and Issues Proceedings on Humanities and Social Sciences. 7(1), pp 210-219. DOI: 10.18844/prosoc.v\%vi\%i.4900

among other things by using cheap construction materials (paper, plastic, small numbers of components and modules). They are available in the regular retail network.

With regard to users, kits can be divided as follows:

- beginners - the purpose of the kit is to provide an introduction to the issue of electrical engineering and to acquire related basic skills;

- advanced users - the purpose of the kit is to expand existing knowledge and skills, as well as facilitate the formation of basic habits;

- very advanced users - the purpose of the kit is to expand knowledge, skills and habits as much as possible, with the only limitations being the ones imposed by the kit's didactic and technical specifications.

In a kit, there are of course electrical and mechanical connections, or even mechanical couplings (such couplings are made between two connection units, one of which contains a little engine, while the other one is fuelled by a mechanism). The specific design of the connections can be viewed as one of the kit's important qualities. This is significant, especially from the perspective of school practice, since technical specifications affect the didactic use of any electrotechnical kit. Depending on the design of connections, kits can be classified as follows:

- those whose connections cannot be disassembled (soldered connections);

- those whose joints can be disassembled (magnetic, spring-based, screw-based, plug-in smooth and spring-loaded or special connections, such as pin-based).

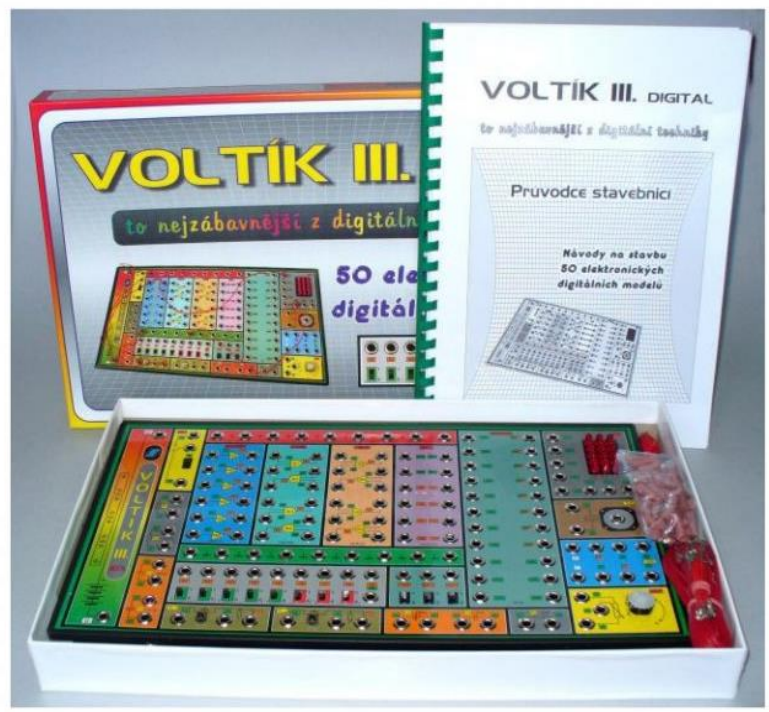

Figure 1. An example of the electrotechnical kit whose components are firmly attached to the support boardVoltík III. Source: https://www.voltik.cz/stavebnice-voltik/voltik-3/

According to Novak (1997), connections that can be disassembled also include wrapped ones, although we do not consider them reliable and thus possible to employ in practice due to their low electrical conductivity.

The placement of components can be another aspect of classifying electrotechnical kits: 
1. Firmly attached to the support board (a single kit can include several support boards)-connections are made either by a system of spring contacts, with insulated conductors slid into their ends, or by a system of sockets (plug-in joints) - i.e., connections are made by conductors tipped with banana plugs or by a system of connection screws/clamps, as is the case of, e.g., the VOLTík kit (Figure 1).

2. Placed on support boards or inside functional units. These basic kit sections are usually placed on the main attachment board, although not always - they can be separate. If used, the attachment board can be perforated, magnetic, based on the stands or on a system of attachment strips or lateral contacts. The Electra I. electrotechnical kit is one such example (Figure 2).

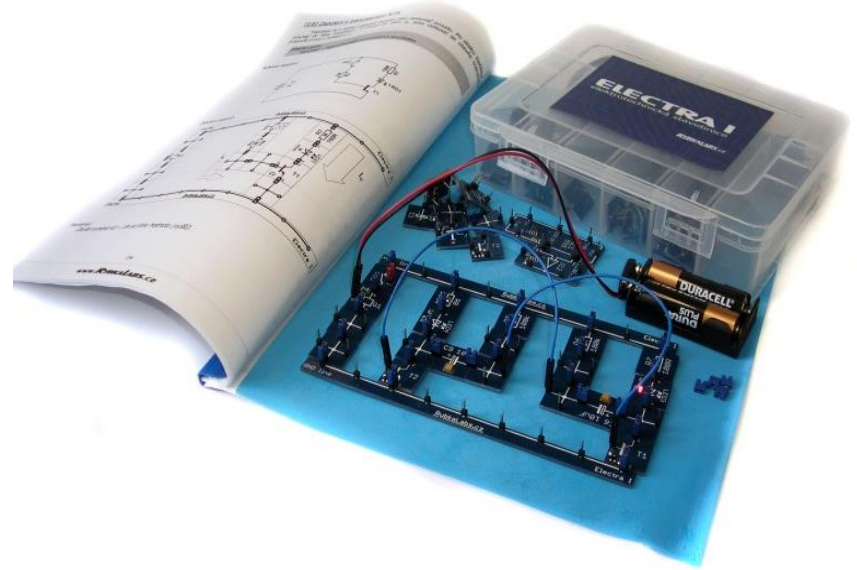

Figure 2. An example of a kit whose components are placed on functional units. The Electra I electrotechnical kit. Source: https://www.hamshop.cz/pro-deti-c33/elektrotechnicka-stavebnice-electra-i-i295

3. Virtual-created by a simulation programme, with software. Naturally, the indestructibility of this type is a strong advantage (if we assume that the computer is not destroyed or that the programme itself does not crash). These systems can have different forms; for example, they can operate solely on the basis of an electrical pattern for analysing electrical circuits. In this category, the PSpice simulation programme is a typical example, as are virtual electro-laboratories which uses the graphic form of individual components and appliances to model an electrical circuit (Figure 3).

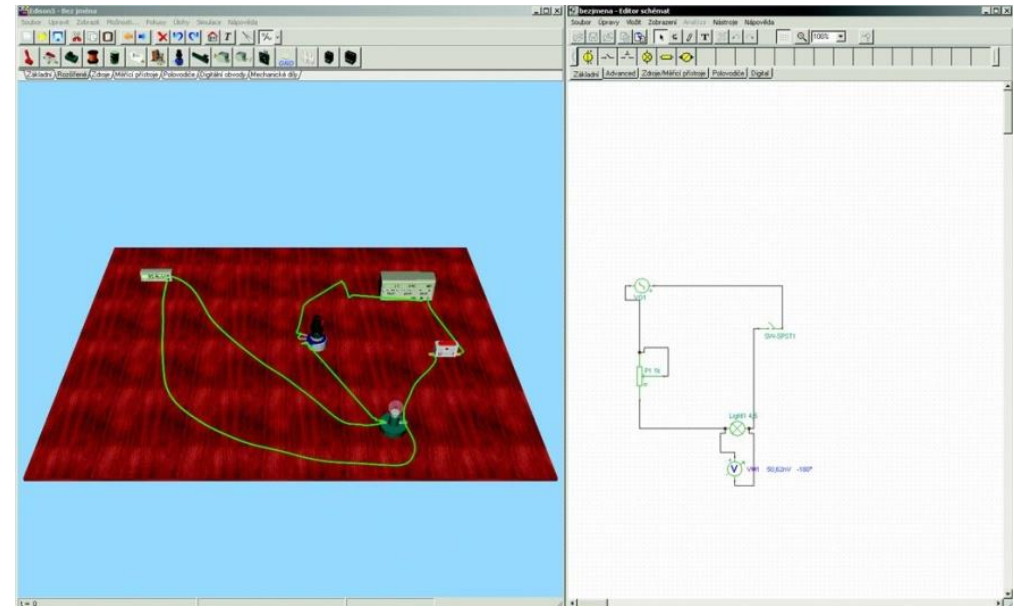

Figure 3 An example of a virtual kit-the multimedia Edison 5.0 laboratory. Source: https://www.terasoft.cz/czpages/cd_edison5.htm 
However, what is crucial in the case of electrotechnical kits, especially those meant to be used in the school environment is the pedagogical perspective. That is why a classification based on the method of the kit's incorporation into teaching should be considered an important and a primary factor. According to Novak (1997), there are demonstrative and student's electrotechnical kits. Nowadays, when digitisation is fundamental not only in the industrial sphere, this classification must be somewhat reassessed, as kits can perform other educational functions than the other two mentioned earlier. Naturally, their role is determined mostly by a teacher's choice of teaching methods and by his or her approach. A couple of examples are given as follows:

a) Demonstrative kits (Figgure 4)-these kits not only serve the purpose of demonstration, of illustrative guidance provided by the teacher, but also of testing the student's knowledge. In order to be able to fulfil this purpose, the kit should be well arranged and visible. The teacher should use demonstrative kits to appropriately assemble electrical circuits, especially in a way that reflects the connection pattern. Circuits are assembled from individual components or function blocks placed below (inside) support boards, with a pattern corresponding to particular components or function blocks drawn earlier. Supporting boards can be attached and connected to a magnetic board or to a vertical perforated panel, or to a system of guide strips hung from the blackboard (demonstration measurement tools can sometimes be hung this way, usually in case of digital or analogue devices with a large and sufficiently visible scale or screen). With demonstrative kits, all components might not be exposed, but if they are (as they should be in the interest of illustration), they should be clearly visible (it is a good idea to use a piece of magnifying glass, for example).

b) Student's kits (Figure 5) - also known as a frontal kit. With this type of kits, what is required is a maximum resistance against any intentional or unintentional mechanical or electrical damage to the components or functional blocks and connection systems. Therefore, resistance and safety must be emphasised. Individual fragile components, e.g., transistors or diodes, are protected from damage (destruction) by current-limiting resistors incorporated into the inlet. Support boards in the form of perforated panels or various systems of guide strips/pegs can be attached and connected vertically or horizontally. Frequently, support boards are also used as assembly boards, where components are placed in different ways.

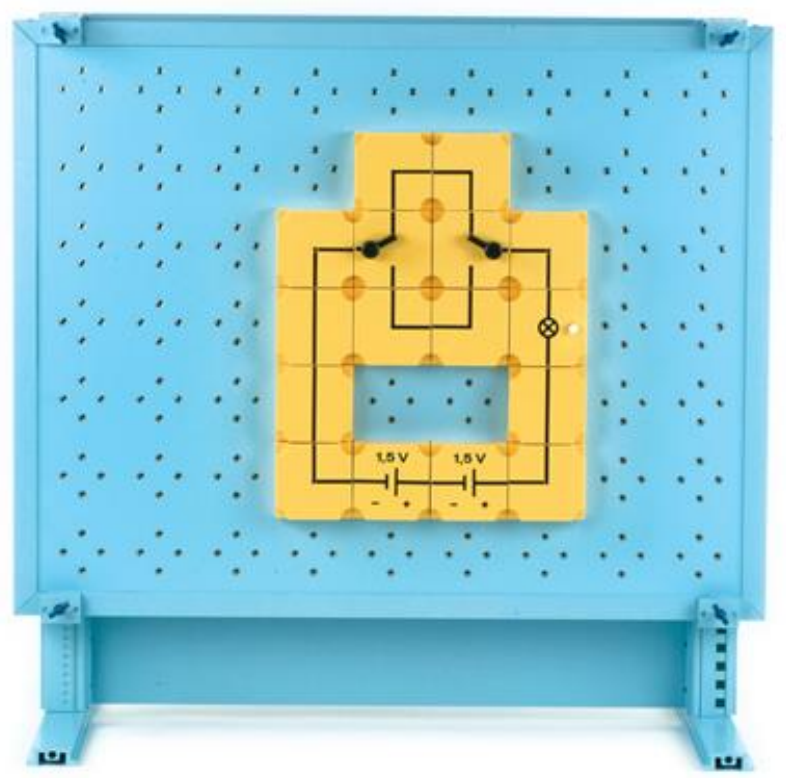

Figure 4. An example of a demonstrative kit-Didaktik. Source: https://www.didaktik.cz/demo_elektrina.html 


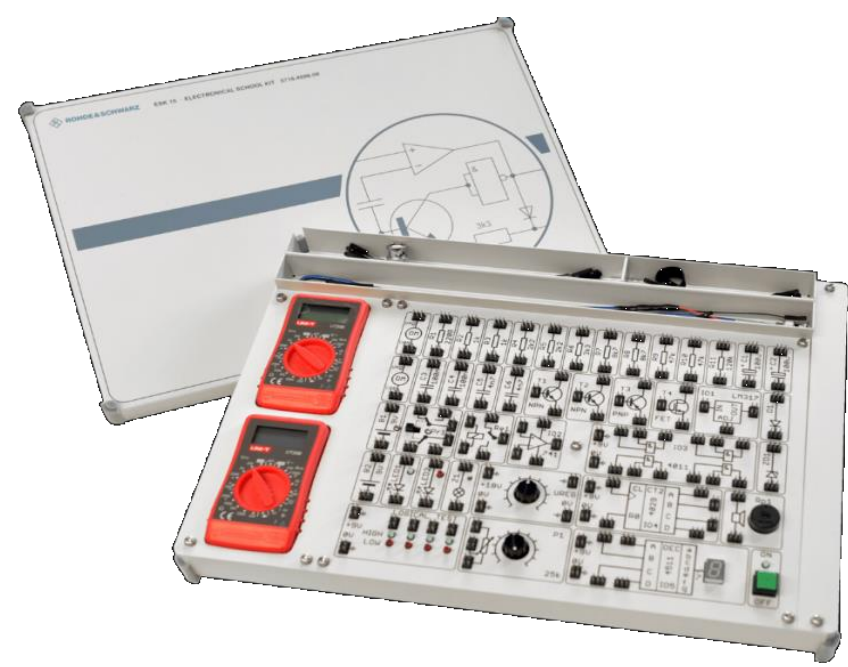

Figure 5. Example of a student's kit - R\&S ${ }^{\circledR}$ ESK15R. Source: http://www.skolnistavebnice.cz/

a) Universal kits-a concept where a kit can be used for both of the above-mentioned purposes, i.e., as a demonstrative and student's kits. This is not a new concept; only the structure is adapted to serve the universal function. The design has one disadvantage, namely the size of the modules (large forms are suitable for demonstrative types, while student's kits do better with a smaller size). Support boards in the form of perforated panels also serve as assembly boards and can be attached as well as connected (or hung) horizontally or vertically.

Electrotechnical/electronic kits of the a)-c) types have only one purpose only-to introduce the basics of electrical engineering in the school environment, regardless of whether students are beginners or advanced (primary school students, or secondary school/college students), to make it possible for the teacher and student to work together. Their chief characteristic, however, is a meagre possibility of combining them with other kits or blocks and with other fields, such as cybernetics, automation, system management, virtualisation, experiment management with the use of tablets or partial modelling in the virtual environment. Considering the current digitisation requirements, all of this should be an integral part of students' preparation. A solution to this issue is offered by different types of virtual or semi-virtual systems which can suitably connect the virtual world to reality (after all, virtual kits have already been mentioned).

a) Virtual kits reflect the current technological possibilities of computer systems. They can be used for the purpose of studying and demonstration, depending on the size of the visual medium used (screen, interactive board, projection screen with a data projector, etc.). This is a computer type whose components or modules are generated by means of a software. These simulation programmes give students a sense of reality through simulated phenomena which are modelled by a computer (Lanicek, 2002). Computer simulations replicate/imitate the actual physical phenomena and processes that take place in electrical circuits. If implemented and used correctly, computer simulations can rather effectively facilitate the acquisition of knowledge and skills, especially in cases of price range, but also feasibility and safety are determining factors (Michael, 2001). Basically, virtual kits are a closed system wherein the possibility of any further expansion is strongly limited by the database of components and devices. Since users usually are not well-versed in source codes and thus cannot interfere in the programme's structure, they must contact the manufacturer in order to expand the programme. On the other hand, the assembled circuits are easy to navigate (this, however, is affected by the user's approach to the proposal), the arrangement of individual components as well as function blocks, including the connecting wire (conductors) guides, is determined by the connection pattern and the programme itself. There is one disadvantage, namely that students 
Serafin, C., (2020). Teaching electrical engineering or technology in a fun way. New Trends and Issues Proceedings on Humanities and Social Sciences. 7(1), pp 210-219. DOI: 10.18844/prosoc.v\%vi\%i.4900

cannot see any real components and most of all cannot touch them. The only thing they see is either schematic marks, or drawn models. As a result of this, students lose their ability to imagine material reality, and underestimate safety hazards. Safety in particular is a crucial factor in the area of electrical engineering. This concerns safety in regard to connecting the circuit as any mistake can lead to the destruction of components (in the virtual environment, a part of the circuit that has suffered a minor damage can naturally be replaced). However, protection from electrical injuries is also an issue. since underestimating such hazards can have very serious consequences.

\section{Conclusion}

The teacher uses words, symbols, patterns, models and real objects to communicate with students. There are a substantial number of transitional abstraction levels between words, symbols and concrete experiences. Models of technical reality and the process of modelling constitute the basic idea which accompanies the creation and application of electrotechnical kits. Working with electrotechnical kits develops a student's technical imagination as a significant intellectual activity which is an immensely important and integral part of technical thinking. Technical imagination and technical thinking are two abstraction components whose content focuses on the area of technics and which cannot be separated from one another. In fact, technical imagination greatly affects the development of technical thinking.

It follows from what has already been stated, that the point of working with electrotechnical kits is for a student to discover an analogy between the original and pseudo-original, based on a model. Considering the conformity between the structure of both systems and their function properties, this is a borderline case of similarity between the two systems. The design of any electrotechnical kit is the umbrella issue for the defined sphere of analogy.

The examined technical original whose model we create with an electrotechnical kit, with the help of a pseudo-original, is actually any 'electric device', i.e., a device which functions or operates based on the effect of electric or magnetic phenomena (or both at the same time). Any electric device is a system. Such systems have sub-systems, meaning their individual active and passive elements. If we abstract the ideal and real terms, then a matching system can be applied to all thematically corresponding kits, one whose sub-systems constitute individual independent function units or connection units. Since this concerns transmissions, with the structure of the reproduced phenomenon maintained within the structure of the phenomenon being reproduced, we can call this process modelling.

Modelling as a creative activity is a part of technical experiments which are an important component of the cognitive process and an indisputable part of the modelling process, and therefore also of working with electrotechnical kits. In the context of schools, we call this an educational technical experiment. It concerns the implementation of the heuristic method of exposing new knowledge by means of a sophisticated procedure of examining, observing, measuring and evaluating the observed or otherwise sensorially (subjectively) perceived reality, including any reality (objectively) discovered by exact means, i.e., by measuring. The goal was to reveal new information about a phenomenon, material, etc.

\section{References}

Damy, A. \& Plascencia, M. G. L. (2020). Interdisciplinary block of learning challenges. Contemporary Educational Researches Journal, 10(1), 21-27. doi:10.18844/cerj.v10i1.4611

Dostal, J. (2004). Zarazeni elektrotechnickych stavebnic do systemu elektrostavebnic (Including electrical kits in the system of electrical kits). e-Padagogium [2020-03-14]. Retrieved from https://e-pedagogium.upol.cz/ artkey/epd-200401-0002_zarazeni-elektrotechnickych-stavebnic-do-systemu-elektrostavebnic.php 
Serafin, C., (2020). Teaching electrical engineering or technology in a fun way. New Trends and Issues Proceedings on Humanities and Social

Dostal, J. (2015). Elektrotechnicke stavebnice a jejich vyznam pro vzdelavani (Electrical engineering kits and their importance for education). Olomouc, Czech Republic: Univerzita Palackeho v Olomouci

Feyisayo, D., Kareem, A. \& Oluwasegun, P. (2019). Effects of English and Yoruba interpreted biology picture label as an advanced organiser on students' learning outcomes in senior secondary schools in Ife East local government area. Contemporary Educational Researches Journal, 9(3), 57-65. doi:10.18844/ cerj.v9i3.4285

Geddes, S. M. (2013). Advanced physics. Heidelberg, Germany: Springer Customer Service Center Gmbh.

Hajerova-Mullerova, L, Doulik, P. \& Skoda, J. (2005). Zakladni aspekty rizeni ucebni cinnosti zaku jako aktivni konstrukce poznani (Basic aspects of pupils learning management as an active construction of knowledge). Technologia vzdelavania, 8(8), 12-16.

Hendl, J. (2005). Kvalitativní vyzkum: zakladní metody a aplikace (Qualitative research: basic methods and applications). Praha, Czech Republic: Portál

Keser, H. \& Semerci, A. (2019). Technology trends, Education 4.0 and beyond. Contemporary Educational Researches Journal, 9(3), 39-49. doi:10.18844/cerj.v9i3.4269

Knapek, Z. \& Titera, D. 2002. Rukovet' sberatele hracek (Toy collector handle). Olomouc, Czech Republic: Rubico. ISBN 80-85839-74-1

Lanicek, R. (2002). Simulacni programy pro elektroniku (Simulation programs for Electronics) (2nd ed.). Praha, Czech Republic: BEN.

Marszalek, A. (2001) Elektronika w edukacji technicznej dzieci i młodziezy (Electronics in technical education of children and youth). Rzeszow, Poland: WSP.

Michael, Y. K. (2001). The effect of a computer simulation activity versus a hands-on activity on product creativity in technology education. Journal of Technology Education, 13(1).

Oyetoro, O., Grace, O. \& Adesina, B. (2019). Interest and learning approaches as discriminating factors in the performance of senior secondary school students in economics. Contemporary Educational Researches Journal, 9(1), 1-13. doi:10.18844/cerj.v9i1.3873

Stoffa, J. (2000). Terminologia $v$ technickej vychove (Terminology in technical education) (2nd ed.). Olomouc, Czech Republic: PdF UP.

Vanecek, D. (2016). Didaktika technickych odbornych predmetu (Didactics of technical subjects). Praha, Czech Republic: CVUT. ISBN 978-80-01-05991-3

Yavuz, F. \& Kurt, F. (2019). Developing young learners' vocabulary retention through adapted Turkish educational games in EFL environment. Contemporary Educational Researches Journal, 9(3), 66-73. doi:10.18844/cerj.v9i3.4301 